\title{
ESCOLA NORMAL DO PARÁ: ASPECTOS HISTÓRICOS, ECONÔMICOS E SOCIAIS ACERCA DA CONSTITUIÇÃO DOS IDEAIS DE INSTRUÇÃO E FORMAÇÃO DE PROFESSORES ENTRE A CLASSE DIRIGENTE DA PROVÍNCIA DO GRÃO-PARÁ (1850-1871)
}

\author{
Rogério Guimarães MALHEIROS \\ Grupo Futuro Educacional de Canaã dos Carajás \\ rogeriomalheiros@yahoo.com.br \\ Genylton Odilon Rêgo da ROCHA \\ Programa de Pós-Graduação em Educação/ICED/UFPA \\ genylton@gmail.com
}

Resumo: Este artigo tem por objetivo o percebimento da constituição imagética acerca do ideal de instrução e de formação de professores que fora implantada na Província do Grão-Pará na segunda metade do século XIX. Neste sentido, como nosso objeto de estudo está demarcado no passado, desenvolvemos este trabalho pelo viés qualitativo e de cunho documental, de forma que para sua análise utilizamos conceitos e técnicas da análise do discurso, na perspectiva de Mikhail Bakhtin. No campo da história, teorica e metodologicamente, demarcamos este trabalho na perspectiva dos Annales. Destarte, utilizamo-nos de Relatórios dos Presidentes da Província do Pará, de relatos de viajantes, além de dados socioeconômicos que melhor embasaram nossa narrativa, levando-nos a depreender as nuanças politicas e sociais acerca da constituição dos ideais de uma instrução e de um processo de formação de professores que pudessem garantir a ilustração da sociedade e anseio social pela industrialização da Província.

Palavras-chave: Civilização e Progresso. Discursos Políticos. Escola Normal do Pará. Instrução. Modernidade.

Abstract: This article aims at the creation of awareness about the ideal imagery of education and training of teachers who had been deployed in the province of GrandPará in the second half of the nineteenth century. In this sense, as our object of study is marked in the past, we have developed this work by the bias and qualitative nature documentary, so that we use for analysis concepts and techniques of discourse analysis, in view of Mikhail Bakhtin. In the field of history, theoretically and methodologically, we established this work from the perspective of Annales. Thus, we use the Report of the Presidents of the Province of Para, reports of travelers, and 
socioeconomic data that best based our narrative, leading us to deduce the nuances about the political and social ideals of the constitution of an education and a process of teacher training that could guarantee the illustration of society and social desire for industrialization of the province.

Keywords: Civilization and Progress. Political Speeches. Para Normal School. Education. Modernity.

A promoção de uma ordem social e de mecanismos para alinhar o Império do Brasil ao nível de civilização alcançada por nações, em especial de países europeus, mas também dos Estados Unidos da América, como necessários para o progresso do Brasil, fora a égide discursiva dos políticos e administradores do Império. Discursos estes que também estiveram presentes entre os políticos e administradores da Província do Grão-Pará, haja vista a todo o momento, em seus Relatórios, artigos e publicações em geral, estavam sempre se reportando a esses ideais de modernidade, progresso, ordem e civilização.

Neste momento, a capacidade de progresso e civilização de um país era associada ao nível de desenvolvimento econômico alcançado por eles, de sua capacidade produtiva, o que segundo o historiador Ilmar Rohloff de Mattos (1994, p. 238-274), em um estudo acerca da constituição da classe dominante do Brasil no segundo reinado, os saquaremas, esteve presente nas ações e discursos dessa classe em ascensão, evidenciando que para a expansão de seus quadros e de suas perspectivas, os mesmos teriam que estabelecer e manter uma ordem e promover mecanismos para a civilização.

Nesta perspectiva, a ordem significava a organização da sociedade dentro das representações existentes, entre os políticos imperiais, de uma hierarquia social definidora de papéis e funções diferenciadas e reservadas para cada grupo, de acordo com as posições por elas ocupadas, o que, segundo Mattos (op. cit.), caracterizaria a formação do Estado Imperial brasileiro.

A civilização, neste sentido, está para além de se garantir ao Estado Imperial à ordem, como concebida acima, mas consistia em estabelecer o primado da Razão, por meio, especialmente, da instrução, o que significaria superar “a 'barbárie dos Sertões' e a 'desordem' das Ruas” (MATTOS, Ibid., p. 245). 
Para esta elite do Império, os saquaremas, o resultado desta difusão da razão na sociedade, por meio da instrução pública, resultaria na constituição de um espírito de associação, bem como pela adesão, por parte desta mesma sociedade, aos projetos políticos da Corte.

Para Mattos (Ibid.), a civilização representaria, na concepção dos saquaremas, de um lado, o alcance da ordem, por outro, consistia na incorporação, por parte da população livre e pobre e da escrava, de noções como o princípio de respeito às leis e às autoridades e de trabalho operoso e rentável. Neste sentido, para a elite dirigente do Império, após o processo de promoção da ordem e da civilização, portanto, é que a sociedade estaria apta a usufruir dos benefícios do progresso, o qual representaria o triunfo final daquelas duas noções, ordem e civilização, consubstanciadas nas melhorias materiais e morais que lhes seriam proporcionadas.

Neste contexto, a instrução pública ganha destaque como elemento propulsor destes ideais de ordem, progresso e civilização presentes nos discursos da elite dirigente imperial. Assim, após esta percepção inicial, evidenciamos que os modelos de instrução europeia ganham destaque entre esta classe dirigente, em especial o modelo francês, que chegam ao Brasil por meio dos intelectuais nacionais que, após viagens realizadas aos "grandes centros" europeus, como França e Inglaterra, trazem consigo ideias e modelos lá vigentes. A Europa, neste momento, como bem Pontuou René Remond (2004), era o exemplo de modernidade a ser seguido.

Segundo Jeffreey Needel (1993), essa influência, que marcou de modo indelével o Segundo Reinado, pode ser observada no planejamento urbano, na arquitetura, na literatura, nas instituições de ensino, na moda, nos hábitos da elite. A França e a Inglaterra se apresentavam aos brasileiros do século XIX como exemplo de tudo o que houvesse de melhor em termos de civilização.

Jacques Le Goff (op. cit., p. 185) identifica os termos "modernismo", "modernização" e "modernidade" como uma herança histórica da querela acerca da dualidade antigo/moderno. Segundo o referido historiador, "[...] a Revolução Industrial vai mudar radicalmente os termos da oposição no par antigo/moderno, na segunda metade do século XIX e no século XX".

A modernidade, neste sentido, a partir da segunda metade do século XIX, apresenta-se como um conceito intimamente relacionado à estética, 
a mentalidade e aos costumes de uma dada sociedade. O próprio termo "modernidade" é lançado por Baudelaire (1863 apud LE GOFF, 2003) na década de 1860, que, segundo Le Goff (op. cit., 194), "dá ao significado de moderno uma nuança que o liga aos comportamentos, costumes e decoração. 'Cada época', diz, 'tem o seu porte, o seu olhar, o seu gesto'”.

O filósofo Henri Lefebvre identifica uma dualidade entre os temos "modernidade" e "modernismo", enfatizando que:

\begin{abstract}
A modernidade difere do modernismo, tal como um conceito em via de formulação, na sociedade, difere dos fenômenos sociais, tal como uma reflexão difere dos fatos [...]. A primeira tendência - certeza e arrogância - corresponde ao Modernismo; a segunda - interrogação e reflexão já crítica -, à Modernidade. As duas, inseparáveis, são dois aspectos do mundo moderno (LEFEBVRE, 1962, p. 10, apud LE GOFF, 2003, p. 195).
\end{abstract}

Le Goff (Id., Ibid.) complementa o pensamento de Lefebvre afirmando que "a modernidade é o resultado ideológico do modernismo". No entanto, refere-se mais a ideologia do inacabado, da dúvida e da crítica, ou seja, trata-se também de um incentivo ao novo, à criação, ao ineditismo. O que para Aron (1969, p. 287), está relacionado “a ambição, retomando a fórmula cartesiana, de ser mestre e possuidor da cultura, graças à ciência e à técnica".

O valor atribuído à cultura europeia configurou-se também como uma aspiração em recriar nos principais centros do Império do Brasil um estilo de vida em consonância com os padrões europeus, que caracterizariam uma forte influência nos discursos e mecanismos legais de instrução pública no século XIX, fato que abordaremos mais detidamente por meio dos dispositivos legais que normatizavam a instrução pública na Província do Grão-Pará, na segunda metade do referido século. Destarte, durante o período imperial brasileiro, a elite intelectual do império, mais especificamente a do Pará, procurava se aproximar e se apropriar das ideias pedagógicas francesas, com o intuito de dar legitimidade às medidas implementadas na área da educação, sendo significativo o número de colégios nos quais o ensino estava centrado na língua e na cultura francesa, que se disseminaram pelos principais centros urbanos do Brasil imperial. 
Neste contexto, no século XIX, podemos constatar, por meio da historiografia nacional e pela análise dos dispositivos legais que normatizavam a instrução pública, a orientação francesa nas escolas, na formação dos professores e nos livros elaborados para a educação de crianças e jovens. Para Needel (Ibid., p. 75), "a instrução seguia a receita da França da Restauração: humanista, conservadora e católica”, na qual os rapazes adquiriam uma formação intelectual e as moças o "verniz" e refinamentos necessários a uma boa esposa.

Neste sentido, não podemos deixar de ressaltar que esta concepção de modernidade também trouxe consigo a ideia de uma sociedade baseada na razão, no cientificismo, na industrialização, na produção de novas tecnologias, na internacionalização do mercado, no fortalecimento dos Estados nacionais e seus mecanismos de controle social e, principalmente, na refutação de antigos hábitos sociais.

Após o percebimento destas questões iniciais, torna-se necessário enfatizarmos que este artigo tem por objetivo central demonstrar a circulação de ideias que permearam os discursos das autoridades provinciais acerca da instrução pública, na segunda metade do século XIX, de forma que possamos depreender a égide discursiva dos políticos, administradores e intelectuais da época para a constituição imagética de um modelo de instrução capaz de promover a razão, a moral e o cientificismo na Província do Grão-Pará, bem como no Império do Brasil.

É interessante ressaltarmos que o conteúdo de um discurso só adquire significado quando correlacionado aos outros discursos ou práticas do momento em que são constituídos, o que Bakhtin (2010) postulou como intertextualidade, isto é, o processo de incorporação de enunciados de um texto em outro.

As contribuições da teoria bakhtiniana são de suma importância para o entendimento dos pressupostos discursivos das autoridades políticas e intelectuais da Província do Pará neste trabalho que ora apresentamos, haja vista quando Bakhtin aborda a formação do eu, o mesmo ressalta que o indivíduo não pode ser considerado isoladamente, estando sujeito, sua constituição, a partir da interação verbal que estaria no centro das relações sociais. Neste sentido, a polifonia, concebida como a ciência do dialogismo, também se configura como parâmetro necessário para o percebimento das constituições discursivas por meio da interação verbal e da intertextualidade (Cf. BAKHTIN, 2009; 2010; BRAIT, 2005).

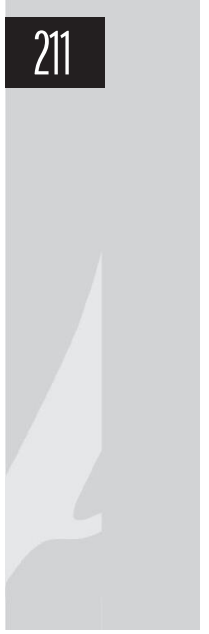


Bakhtin postula ainda que por meio da perspectiva histórica e social é possível apreender a linguagem e a criação ideológica que, baseado na diversidade cultural, o discurso ideológico estaria relacionado a uma dialética da linguagem, constituidora de uma perspectiva do discurso vinculado à prática social e coletiva de uma dada sociedade, e no caso de uma temporalidade demarcada no passado, seriam observadas por meio de seus registros, no caso desta pesquisa, documentação escrita, onde podemos depreender as especificidades do discurso e suas influências ideológicas e conceituais a partir das prerrogativas da intertextualidade (Cf. BRAIT, 2009).

Neste sentido, situamos nosso trabalho como uma contribuição para o debate acerca da história da educação do Pará e, por conseguinte, do Brasil, pois temos como premissa o trabalho de historiador, que nos direciona a estabelecer as especificidades das representações de outras épocas, neste caso, a segunda metade do século XIX na Província do GrãoPará, sem procurar compreender seus significados a partir de padrões ou conceitos atuais. Ou seja, procuramos estabelecer nossas análises a partir do que Lucien Febvre (1970) denominou de "instrumental intelectual" de uma época.

Delimitamos nossa análise na segunda metade do século XIX, haja vista inúmeros estudiosos apontam que este período fora, no Brasil, um espaço de tempo de expressivas transformações, na qual se percebe meandros políticos e ideológicos que marcaram a história do país. Fora um tempo de vigência de processos de extrema relevância para os estudos relacionados a diversas temáticas do campo social, econômico, político, cultural, educacional, entre outros.

A relevância de estudos que problematizem questões referentes ao campo educacional, mais especificamente, dentro do campo da História da Educação, está intimamente relacionada a uma linha de pensamento e preocupação dos novos estudos historiográficos, postulados pela chamada "história nova", também conhecida como terceira geração dos Annales, que defendem a necessidade de se pluralizar os objetos de investigação e os agentes do processo social.

Ressaltamos que os estudos baseados em documentos, em especial os de ordem historiográfica, procuram tecer observações e conclusões, por meio de análises dos conteúdos dos mesmos, à luz da consulta bibliográfica 
acerca do período. Neste sentido, a concepção do documento como monumento, fundamentada na "Nova História", postula que toda fonte histórica "exprime o poder da sociedade do passado sobre a memória e o futuro" (LE GOFF, 2003, p. 10). Dessa forma, concebido como produto de uma sociedade, o documento manifesta o jogo de força e as manobras políticas dos que detêm o poder, bem como as especificidades sociais e culturais de uma determinada época.

Temos a clareza de que não se tratam de produções humanas isentas ou ingênuas, mas traduzem leituras e modos de interpretação do cotidiano vivenciado por um determinado grupo social em um dado tempo e espaço. Neste sentido, a narrativa se apresenta como uma interpretação do pesquisador, a partir de um suporte teórico e metodológico fornecidos pelos documentos consultados.

Segundo o filósofo, teólogo e historiador Michel De Certeau:

\begin{abstract}
Toda pesquisa histórica se articula com um lugar de produção sócio-econômico, político e cultural [...]. Ela está, pois, submetida a] imposições, ligada a privilégios, enraizada em uma particularidade. É em função deste lugar que se instauram os métodos, que se delineia uma topografia de interesses, que os documentos e as questões, que thes serão propostas, se organizam (CERTEAU, 2008, p. 66.).
\end{abstract}

Assim, cada documento, necessariamente, se vale de uma rede de significados que contribuíram para sua confecção, dessa forma, possui uma intencionalidade, isto é, nenhum discurso está destituído de valor, ou seja, são escritos com base em um universo imagético que se fará presente em sua confecção e que serão interpretados pelo pesquisador. Tratam-se de representações de um tempo passado e que passam a ser analisadas e interpretadas por meio da escrita, que se valerá das marcas temporais presentes na fonte, em qualquer que seja seu suporte, a fim de conferir inteligibilidade e credibilidade à narrativa. Uma escolha que necessariamente significa uma recusa, uma renúncia a uma infinidade de outras possibilidades, o que caracteriza o olhar direcionado do pesquisador.

Nesse aspecto, percebemos que na decifração das práticas sociais, considerando sua temporalidade, o importante é intuir as tensões existentes entre as estratégias discursivas e as técnicas de apropriação, 
destarte, o desafio fundamental para o pesquisador é perceber a relação que se estabelece entre os textos disponíveis e as práticas sociais geradoras dos mesmos.

\title{
1 A Província do Grão-Pará e sua modernização: aspectos econômicos e sociais
}

\begin{abstract}
As duas províncias de que tenho tratado são sem duvida de entre todas as que compõem o grande Império do Brazil as que mais promettedor futuro apresentam; a riqueza do sollo, as innumeras vias fluviaes, a diversidade de seus productos naturaes, o augmento rapido de suas cidades e populações, o sempre crescente número de vapores e navios que demandam seus portos são seguros prenuncios que em dois ou três decemnios a Amazônia será uma digna emula das primeiras provincias do Império [...] (ABREU, op. cit., p. 18).
\end{abstract}

O Barão de Marajó, autor da epígrafe em destaque, membro da elite política da Província do Grão-Pará, que presidiu a Província do Amazonas na década de 1860 e, posteriormente, a do Pará na década de 1870, Bacharelou-se em Filosofia e Matemática na Universidade de Coimbra em Portugal, e filiado a Academia de Ciências de Lisboa, destacou-se por suas produções literárias acerca dos aspectos sócio-político-econômico das Províncias do Pará e do Amazonas, muito em função de sua trajetória política e administrativa nas duas Províncias do norte do Império.

Neste sentido, torna-se salutar reportarmo-nos a esta figura política e intelectual do período em questão, segunda metade do século XIX, uma vez que nos fornece um significativo relato socioeconômico da região amazônica a partir da década de 1850 , por meio da obra intitulada "A Amazônia: as Províncias do Pará e Amazonas e o Governo Central do Brazil", publicada em Lisboa no ano de 1883. Trata-se de um olhar individual, porém permeado de ideologias políticas constituídas a partir de suas relações sociais com uma colegialidade política, intelectual e administrava das províncias em questão.

O Barão de Marajó, na mencionada obra, dedica-se em demonstrar as especificidades amazônicas, suas riquezas e progressos alcançados desde os anos de 1850, de forma que reclama a falta de observância do Governo Central do Império do Brasil acerca das contribuições 
econômicas e cultural que a região vinha depositando à fazenda e a sociedade nacional, além de suas potencialidades inexploradas no campo mineral, evidenciando a falta de reconhecimento do progresso social e econômico que a região vinha alcançando, haja vista tratavam a região de forma preconceituosa e com certo desprezo. O que para o autor, justificaria os discursos emancipacionistas, no entanto, o mesmo defendia o fortalecimento do Império e o reconhecimento das potencialidades das duas províncias amazônicas, que deveriam estar unida ao restante do Império, mas que fossem respeitados e reconhecidos os seus valores.

Os progressos e potencialidades da região amazônica, evidenciadas pelo Barão de Marajó, também são perceptíveis nos discursos presentes nos Relatórios dos Presidentes da Província do Grão-Pará no período que delimitamos para nossa investigação, 1850 a 1871. Por meio destes relatórios e outras fontes publicadas no período, podemos depreender que houve uma significativa elevação na arrecadação da Província do Pará desde a década de 1840, o que os Presidentes e autoridades constituídas atribuíram ao crescente comércio da borracha, que ano após ano vinha crescendo de forma bem acentuada. Fato que podemos evidenciar por meio dos números apresentados no "Relatório dos negócios da Província do Pará", que sintetizamos por meio do quadro a seguir:

\section{Quadro 1 \\ Receitas da Alfândega do Pará (1840 - 1864)}

\begin{tabular}{|c|c|}
\hline Quadriênios & Receitas Médias \\
\hline $1840-1844$ & $277: 178 \$ 609$ \\
\hline $1844-1848$ & $454: 902 \$ 312$ \\
\hline $1848-1852$ & $635: 077 \$ 313$ \\
\hline $1852-1856$ & $1.131: 993 \$ 089$ \\
\hline $1856-1860$ & $1.320: 557 \$ 126$ \\
\hline $1860-1864$ & $1.960: 121 \$ 673$ \\
\hline
\end{tabular}

Fonte: PARÁ, Governo da Província do. Relatório dos Negócios da Provincia do Para. Pará: Typographia de Frederico Rhossard, 1964, pp. 59-60.

Tratam-se de números que demonstram as receitas da alfândega paraense, mas que não evidenciam apenas o comércio gomífero, mas sim os inúmeros produtos exportados pelo porto de Belém, que somados

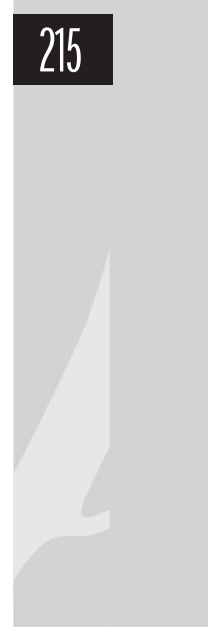


chegam às cifras em destaque no quadro acima. Não estamos deslocando a importância atribuída ao comércio gomífero no período, pelo contrário, queremos apenas elucidar que além da borracha, as exportações de outros inúmeros produtos também estavam contribuindo para a fazenda provincial, a exemplo do Cacau, Arroz, Castanha do Pará, Algodão, Couros, Guaraná, Madeira, entre outros.

Neste sentido, a partir do significativo aumento da arrecadação alfandegária da Província do Pará, como bem podemos notar no quadro de $\mathrm{n}^{\mathrm{o}} 1$, podemos depreender que as ações de reforma urbanísticas e embelezamento da cidade de Belém, neste mesmo período, estiveram intimamente ligadas a esta crescente arrecadação da fazenda provincial, bem como as novas exigências da classe enriquecida por meio deste volumoso comércio, com destaque para as exportações da borracha, que em dado momento chegou a ocupar o segundo lugar das exportações brasileiras para o exterior, possibilitando, na década de 1880, a elevação da tesouraria da Província do Pará à categoria de $1^{\text {a }}$ Classe, pela Câmara dos Deputados do Império. Sendo que a tesouraria da Província de São Paulo, de notável importância devido ao comércio cafeeiro e do porto de Santos, neste mesmo período, ocupava a categoria de $2^{\text {a }}$ classe. O que causou uma reação dos políticos e imprensa paulistana, que reivindicavam para si esta elevação de categoria e não à Província do Pará, haja vista consideravam a economia paraense "ephemera" e "passageira", o que o periódico paraense "Diário do Gram-Pará" classificou como "despeito" (DIÁRIO DO GRAM-PARÁ, agosto de 1882, p. 1).

Acerca desta questão, o Barão de Marajó (op. cit. p. 43) adentra no debate e evidencia que no exercício de 1881 a 1882 a alfândega de Belém rendeu 9812:393\$704, enquanto que a do porto de Santos rendeu 6517:329\$872, uma diferença de 3295:063\$832, o que justificaria a prioridade alfandegária do Pará em relação à de São Paulo. Esta questão da categoria a que deveria ocupar cada Província rendeu ainda intensos debates entre a imprensa paraense e a paulistana, haja vista nas duas províncias foram publicados no ano de 1882 inúmeros artigos que se dedicavam a questão, os de São Paulo questionando a concessão ao Pará e os de Belém respondendo as críticas feitas pelos paulistanos e defendendo a economia da Província, que, vale ressaltar, crescia anualmente. 
Sem dúvidas, o porto de Belém se destaca no cenário nacional, tornando-se um dos portos mais movimentados do Império, muito em função das exportações da goma elástica que cada vez mais fora demandada por inúmeros países de vários continentes, o que acabava por refletir em outros setores da economia interna da Província que, especialmente a partir da década de 1850, passou a ter a sua economia em pleno crescimento, provocando também um aumento na presença de estabelecimentos comerciais na capital.

Segundo dados presentes na fala do Presidente da Província do Pará Manoel de Frias e Vasconcellos dirigida à Assembleia Legislativa da Província em 1 de outubro de 1859, o número de indústrias na Capital da Província naquele ano era de 744 estabelecimentos (Cf. PARÁ, 1859). Já em 1871, o número desses estabelecimentos saltou para 1.055, segundo o relatório do Presidente Abel Graça, o que denota um significativo aumento na quantidade desse tipo de estabelecimento, além de demonstrar a dinamicidade econômica na Capital da Província neste período (Cf. PARÁ, 1871).

$\mathrm{Na}$ comparação entre os dois Relatórios dos mencionados Presidentes da Província do Grão-Pará, percebemos ainda um significativo aumento no número de tipografias da Capital, que em 1859 contava apenas com 4, em 1871 passou a contar com 8, o que denota o cosmopolitismo exacerbado da elite residente na capital paraense da época, ávida em conhecer e se informar acerca de outros países e sobre os fatos transcorridos na corte brasileira.

Fato que podemos observar apenas na capital da Província, pois para o Presidente Couto de Magalhães, em seu Relatório apresentado à Assembleia Legislativa provincial em 15 de agosto de 1864, enfatiza que:

[...]. A industria é o resultado do esforço da intelligencia do homem para satisfazer uma necessidade que apparece. Portanto, em quanto não existir a necessidade, não haverá razão para que exista a indústria. [...]. Crear necessidades, civilisando o povo e dando-lhe instrucção, são os meios de fazer apparecer a industria; são lentos é certo, mas são tambem os unicos e seguros (PARÁ, 1864, p. 7).

Couto de Magalhães chega a esta conclusão após ter realizado uma viagem ao interior da Província, a "zona do Tocantins", quando constatou 
a abundância dos recursos naturais e a relação social dos indivíduos com a natureza, percebendo que a industrialização não interessava àquelas pessoas que habitavam esta porção do território da Província. Neste sentido, o Presidente atribui à instrução pública o papel de, além de promover a civilização, também o de proporcionar a constituição de uma mentalidade industrial entre os cidadãos da Província do Pará, haja vista identificava que os mesmos não possuíam, naquele momento, uma preeminente necessidade de promover a industrialização da Província, muito em função, como bem observou Couto de Magalhães, aos recursos naturais disponíveis para sua subsistência.

Retomando a questão acerca da crescente arrecadação alfandegária da Província do Pará, percebemos ainda que houve na cidade de Belém um significativo aumento no número de habitantes e no custo de vida dos mesmos, fato que podemos notar nos relatos do naturalista Henry Walter Bates (1979, p. 297), quando afirma que "no reverso da medalha", ou seja, em contrapartida as volumosas intervenções urbanísticas da cidade e a sua crescente economia, seus habitantes tiveram que pagar mais caro para se obter gêneros alimentícios, como farinha de mandioca, banana, laranja, entre outros, além de pagarem igualmente mais caro por seus aluguéis, neste sentido, a especulação imobiliária e a produção de alimentos, que se tornou insuficiente para garantir o abastecimento do mercado interno, acabaram por fazer parte deste novo momento que a cidade estava vivenciado.

Neste contexto, o Conselheiro da Província Rego Barros, em sua fala dirigida a Assembleia provincial de 15 de agosto de 1854, evidenciou que:

[...] do preço extraordinário a que tem subido a borracha, $e$ consequentemente do emprego quase exclusivo dos braços na sua extração e fabrico, a ponto de nos ser preciso actualmente receber de outras Provincias generos de primeira necessidade, e que dantes produziamos até para fornecer-lhes (PARÁ, 1854, p. 40).

Bates (1979) em sua segunda visita à Belém, no ano de 1859, elucidou que este fato apresentado pelo Conselheiro da Província, à época, esteve intimamente ligado ao crescente aumento da população de Belém, 
e como bem pontuou o Conselheiro, devido também ao exclusivismo dos "braços" para a atividade de extração da goma elástica, provocando certa crise na produção de gêneros alimentícios na Província. Fato este que podemos notar nas sucessivas falas e Relatórios dos administradores da Província.

Quanto ao aumento da população de Belém, em decorrência da produção gomífera, Anderson (1976, p. 69) afirma que entre os anos de 1849 a 1872, o número de habitantes da cidade de Belém saltou de 16.337 para 30.050, o que denota que a cidade se tornou a principal referência para a exportação da borracha, atraindo cada vez mais pessoas interessadas em lucrar com este comércio.

\section{O surgimento da Escola Normal no contexto da modernização do Grão-Pará}

Leonor Maria Tanuri (2000), em um contexto amplo, ressalta que:

O estabelecimento das escolas destinadas ao preparo específico dos professores para o exercício de suas funções está ligado à institucionalização da instrução pública no mundo moderno, ou seja, a implementação das ideias liberais de secularização e extensão do ensino primário a todas as camadas da população (TANURI, 2000, p. 62).

Demerval Saviani (2009, p. 143), corrobora com a assertiva de Tanuri (2000) afirmando que "[...] a questão da formação de professores exigiu uma resposta institucional apenas no século XIX, quando, após a Revolução Francesa, foi colocado o problema da instrução popular". Neste contexto, depreendemos que é a partir desta questão que deriva o processo de criação das Escolas Normais no Império do Brasil, com a finalidade específica de formar professores.

Estas influências externas para a constituição de uma instrução que fosse capaz de prover a ordem, o progresso e a civilização, isto é, os parâmetros sociais para a constituição de uma sociedade moderna, estiveram presentes nos discursos dos políticos e membros da classe abastarda da Província do Grão-Pará, bem como entre a elite saquarema do Império do Brasil. 
Podemos depreender, por meio desta breve narrativa que ora apresentamos, a tônica discursiva acerca da modernidade, de forma que enfatizamos a próspera economia da Província do Grão-Pará, proporcionada pelo crescimento anual da arrecadação alfandegária atribuída ao aumento da exportação da borracha, como um desses elementos que fizeram com que esta elite local voltasse seus discursos para a constituição de um ideal de instrução e de modernização da cidade de Belém, de forma que a formação do cidadão passava a ser imprescindível para se alcançar os níveis de progresso, civilização e modernidade alcançados pelas nações europeias, como França e Inglaterra, e os Estados Unidos da América.

Tal questão se torna mais relevante se lembrarmos de que políticos de diversas posições ideológicas e administrativa possuíam uma intensa atuação intelectual, como escritores, naturalistas amadores, jornalistas etc., outros com estreita relação com a instrução, seja como professores ou administradores da instrução.

Assim, vale ressaltarmos ainda que as discussões tecidas neste artigo, que primaram por observar as nuanças políticas, econômicas e sociais que permearam o cotidiano da Província do Pará na segunda metade do século XIX, permite-nos desvelar um contexto específico, onde circulou inúmeras ideias e modelos de instrução defendidos por políticos e intelectuais da época como necessários e eficientes para o desenvolvimento e qualidade da instrução pública na Província do Pará, bem como o de promover um anseio pela industrialização da Província entre a população do interior.

Destarte, depreendemos que não se trata de um conjunto unificado e hegemônico, de ideias e modelos, que dentro do qual e em função do qual os políticos, intelectuais, dirigentes e professores determinariam as suas escolhas teóricas e metodológicas para compor seus ideais de instrução pública, no entanto, nos proporciona a visualização de um movimento de circulação de ideias que não determinam suas escolhas, mas nos permite situá-las neste processo. E a partir deste contexto diversificado e, por vezes, antagônico de ideias e modelos de instrução é que irá nos proporcionar a percepção da intertextualidade, bem como da dialética social presentes nos discursos dos Presidentes da Província do Grão-Pará. 
Ante a este contexto de aspirações por uma instrução pública capaz de prover a ordem e a civilização, podemos perceber ainda a hegemonia do método normalista francês entre os políticos dirigentes da Província do Pará, uma vez que é por meio da instauração de uma Escola Normal na Província que os mesmos achavam que estariam resolvidos os problemas da instrução e da constituição de uma sociedade formada por indivíduos civilizados à luz da moral, da razão e do cientificismo.

Neste contexto, a Escola Normal da Província do Pará fora criada por meio da Lei ${ }^{\circ} 669$ de 13 de abril de 1871, no final do Governo do Presidente Joaquim Machado Portela, nascendo já com grandes expectativas, que nas palavras do então Presidente da Província, Abel Graça, a instituição resolveria as causas do atraso da instrução na Província "graças a lei n. 669, e aos regulamentos, que sob as suas bases foram magistralmente organizados pelo hábil administrador, o sr. dr. Portella, meu illustre amigo e antecessor" (GRAÇA, 1871, p. 8).

Ou seja, para a elite dirigente da Província, a Escola Normal desenvolveria e propagaria o ensino no interior da Província, haja vista o próprio Presidente afirmava que o motivo de não se obter relevantes resultados dos investimentos feitos na área da instrução pública, estaria relacionado ao fato de "não termos na capital uma escola normal primaria onde os candidatos ao professorato se habilitassem theorica e praticamente para o ensino" (Id., Ibid.).

Neste sentido, corroboramos com a assertiva de Saviani (2009), quando afirma que a questão do preparo de professores no Brasil emerge desta influência do pensamento e experiência do velho continente, mais especificamente, do pensamento francês pós-revolução de 1789. O autor afirma ainda que a cogitação da organização de uma instrução popular no país surge de forma explícita após o processo de independência política, e que no período de 1827 a 1890, tivemos inúmeros ensaios de formação de professores, haja vista:

[...] esse período se inicia com o dispositivo da Lei das Escolas de Primeiras Letras, que obrigava os professores a se instruir no método do ensino mútuo, às próprias expensas; estendendo-se até 1890, quando prevalece o modelo das Escolas Normais (SAVIANI, 2009, p. 143-144). 
Saviani (2009) afirma ainda que a via normalista de formação docente, apesar de adotada já a partir de 1835, com a fundação da primeira Escola Normal do Brasil, na Cidade de Niterói - Rio de Janeiro, adquire certa credibilidade apenas a partir de 1870 , permanecendo por décadas apenas como uma alternativa ao processo de formação de professores e sujeita a inúmeras contestações.

As críticas tecidas ao modelo normalista eram, em geral, por acharem o modelo extremamente oneroso ao Estado, ineficientes qualitativamente e insignificantes quantitativamente, haja vista o número de professores formados era bem reduzido.

Por fim, ressaltamos que este artigo fora uma forma de, resumidamente, concatenarmos o movimento de ideias e modelos que permearam imageticamente a constituição de uma aspiração política na Província do Pará de uma Escola Normal destinada ao preparo do professor ilustrado e aplicado que se queria como elemento propagador de seus ideais de ordem, progresso e civilização. Ressaltamos que esta narrativa trata de observações preliminares acerca desta constituição discursiva da necessidade de se implantar na Província do Grão-Pará uma escola destinada à formação de professores pelo método normalista, diríamos que tentamos demonstrar as influências que permearam esta constituição imagética de um modelo de instrução.

\section{REFERÊNCIAS}

ABREU, José Coelho da Gama (Barão de Marajó). A Amazônia: as Províncias do Pará e Amazonas e o Governo Central do Brazil. Lisboa: Typographia Minerva, 1883, 112p.

ANDERSON, Robin Leslie. Following Curupira: Colonization and migration in Pará, 1758 to 1930. As a Study in a Settlement of the Humid Tropic. California: University of California, 1976 (Tese de Doutorado em História).

ARON, R. Les désillusions du progress. Essai sur la dialectique de la modernité. Paris: Calmann-Lévy, 1969.

BAKHTIN, Mikhail. Estética da Criação Verbal. São Paulo: Martins Fontes, 2010a. 
. Freudismo. São Paulo: Perspectiva, 2004.

2009.

. Marxismo e Filosofia da Linguagem. São Paulo: Hucitec, $2010 \mathrm{~b}$.

Problemas da poética de Dostoiévski. São Paulo: Forense,

Questões de Literatura e de Estética. São Paulo: Hucitec, 2010c.

BATES, Henry Walter. Um naturalista no Rio Amazonas. São Paulo: EDUSP, 1979.

BRAIT, B. (Org.). Bakhtin: outros conceitos-chave. São Paulo: Contexto, 2006.

CERTEAU, M. A escrita da história. Rio de Janeiro: Forense Universitária, 1982.

DIÁRIO DO GRAM-PARÁ. A abertura do Amazonas. Belém, 7 de setembro de 1867.

DIÁRIO DO GRAM-PARÁ. São Paulo e Pará. Belém, 31 de agosto de 1882.

FEBVRE, Lucien. O problema da descrença no século XVI: a religião de Rabelais. Lisboa: Inicio, 1970.

GRAÇA, Abel. Relatorio apresentado à Assembléa Legislativa Provincial na segunda sessão da 17. Legislatura, pelo Dr. Abel Graça, Presidente da Província. Pará: Typ. do Diário do Gram-Pará, 1871.

LE GOFF, Jacques. História e Memória. Tradução Bernardo Leitão [et al.]. $5^{\mathrm{a}}$ ed. - Campinas, SP: Editora UNICAMP, 2003.

MATTOS, Ilmar Rohloff de. O tempo Saquarema. Rio de Janeiro: ACCESS, 1994.

NEEDEL, Jeffrey D. Belle Époque Tropical: Sociedade e cultura de elite no Rio de Janeiro na virada do século. São Paulo: Companhia das Letras, 1993.

PARÁ, Governo da Província do. Falla dirigida a Assemblea Legislativa da Provincia do Para na segunda sessão da XI 
Legislatura pelo Exm $^{\circ}$ Sr. Tenente-Coronel Manoel de Frias e Vasconcellos Prezidente da mesma Provincia, em 1 de Outubro de 1859. Pará: Typographia de J.R. Guimarães, 1859. Disponível: www. crl.edu/areastudies/LAMP/index.htm

PARÁ, Governo da Província do. O Tocantins e o Anapú. Relatorio do Secretario da Provincia. Pará: Typographia de Frederico Rhossard, 1864. Disponível: www.crl.edu/areastudies/LAMP/index.htm

PARÁ, Governo da Província do. Relatório dos Negócios da Provincia do Para. Pará: Typographia de Frederico Rhossard, 1964, p. 59-60.

REMOND, René. O século XIX (1815-1914). $9^{a}$ Ed. São Paulo: Cultrix, 2004.

SAVIANI, Demerval. Formação de professores: aspectos históricos e teóricos do problema no contexto brasileiro. Revista Brasileira de Educação, v. 14, n. 40, jan./abr. 2009.

O legado educacional do século XIX. $2^{a}$ Ed. Campinas:

Autores Associados, 2006.

TANURI, L. M. História da formação de professores. Revista Brasileira de Educação: 500 anos de Educação. Editores Associados, no 14, mai/ jun/jul/ago.2000, 61-88. Disponível: www.anped.org.br/rbe/rbedigital/ RBDE14/RBDE14_06_LEONOR_MARIA_TANURI.pdf. 